\title{
La Nueva y Bienvenida Ave Fénix
}

\author{
Aurelio de la Vega
}

A través de los tiempos dos escuelas de pensamiento han prevalecido en relación con la visión que un compositor tiene sobre su propio arte. Una de ellas - la más obvia y perdurable - proclama que la música es, sobre toda otra consideración, un arte emocional y comunicativo que no necesita explicaciones, aún cuando la música sea ella misma bastante compleja, como es el caso de la llamada música de arte. Esta postura es axiomática y evidente en el campo de la música popular, las expresiones folklóricas o la música comercial. Hasta Wagner, lo mismo ocurría en el mundo de lo que habitualmente se denomina com música clássica o música culta. La otra postura, muy típica del siglo $\mathrm{XX}$, afirma que la música de arte se ha transformado en un ente tan engorroso y enigmático - cuando no totalmente nihilista, ininteligible y cerebral que se necesitan toda classe de explicaciones para hacerla viable al que la escucha. Después de Schoenberg y su obsesiva, mesiánica, didáctica y filosófica postura, todas las sinnúmeras verbalizaciones que le han seguido forman un crescendo atronador, consiguiendo en muchos casos la dudosa distinción de convertirse en un neurótico auto-examen psicológico, o en discursos y sermones risibles y pedantes repletos de frases pseudo-matemáticas, diagramas, esquemas gráficos y/o aserciones pomposas, quasi-metafísicas. Con justificada sospecha el amante de la música seria de nuestros días se topa con un arte que, por vez primera en la história, necesita ser explicado, diseccionado y analizado para lograr convencer al oyente. Evidentemente no puede dejar de ponerse en tela de juicio la limitada capacidad comunicativa de tal tipo de música.

Inmediatamente surgen preguntas sobre la inevitabilidad de la complejidad de la música de arte contemporánea y su total divorcio de un público para el cual, supuestamente, es creada. ?Es verdad que el compositor occidental de la música culta, continuando el rico y fascinante desarollo de una herencia cultural multi-dimensional, no pudo hacer otra cosa que crear formas expressivas cada vez más abstractas como continuación a la desaparición de la tonalidad? ?Es que hemos tratado, mental y especulativamente, de alterar el órden básico de la naturaleza, yendo más allá de la capacidad física del oído como tan enfáticamente lo ha afirmado George Rochberg - forzando la computadora del cerebro humano a calcular parámetros que están fuera de la memória informativa acumulada? ?Es que la música de arte se ha vuelto tan inhumana que se ha transformado ella misma, a lo Hermann Hesse, en un mero juego de números, fascinante y aparentemente lúcido cuando se ve expresado en la página impresa (bien sea ésta la partitura o una explicación ad nause- 
am de la misma), y tan confuso y nebuloso cuando se escucha en su realidad sonora? ?Hemos conseguido finalmente inventar en nuestro siglo una verdadera Augenmusik que se ha metamorfoseado en arte visual y por lo tanto ha dejado de ser auditivo? ?Somos nosotros los verdugos, los exponentes de una solución final musical, los diseñadores del último capítulo, los enterradores terribles e inevitables?

El exceso de aclaraciones explicativas viviseccionarias, egocéntricas, filosóficas y analíticas que los compositores del siglo XX exhiben, constituyen un interessante y penoso codicilo que retrata la história de la humanidad en nuestra era. Dichas aclaraciones pueden constituir datos jugosos para los musicólogos, los ensayistas y los antropólogos. Pero para la gran mayoría de los amantes de la música éstas permanecem tan obscuras y herméticas como lo sigue siendo Die glückliche Hand para el público en general después de más de casi ochenta años de existencia. Uno se pregunta si realmente existem muchos conversos que hayan gozado más una composición de uno delos super-verbalizadores después de leer y reler (o tratar de leer) uno de esos magníficos y pedantes escritos analíticos que éstos gustan de redactar para publicaciones esotéricas especializadas en la música de nuestro momento.

En nuestro tiempo la palabra impresa ha llegado a ser un arma poderosíssima y el conocer su predomínio mágico, casi hipnótico, ha permitido que muchos compositores poco notables (quienes hubieran permanecido desconocidos y alejados de toda comunicación artística con los grupos humanos de su momento) formen toda clase de grupos y anti-grupos. Estas diversas falanges constituyen verdaderas mafias que no son sino sociedades de adilación mutua que ejercen gran poder y las cuales, frecuentemente, son las responsables de muchas promociones académicas. Sobre todo, estas agrupaciones infunden al recipiente de los variados homenajes que se programan un sentido de importancia muy agradable y bienvenido. Claro está que estas toneladas de escritos analíticos, de fanfarrones ensayos, de fatuas y pedantes "notas al programa" escritas por los propios compositores, y de entrevistas "dialogueras" donde se repartem honores y premios al genio de turno, son meramente documentos inermes: éstos jamás podrán destruir obras de verdadera sustancia musical ni resucitar las que nacen ya cadavéricas. Mayormente, son objetos inocuos que actúan catárticamente como ritos de purificacion, y que sirven de cómodas válvulas de escape psicológico.

A pesar de que la cantidad de cuartillas superficiales, vacías y bombásticas que se han escrito sobre la música del siglo $\mathrm{XX}$ es enorme, el número de escritos sobre el mismo tema, con proyección de crítica estética séria, permanece siendo exiguo. Desgraciadamente, muchos de los trabajos de este segundo tipo que existen poseen frecuentemente un matiz político evidente (como cuando se leen esas encomiásticas crónicas sobre compositores que se mueven dentro de la hasta mui recientemente poderosísima órbita izquierdo-marxista), o tienen un alcance limitado (concentrados solamente en ciertos países y regiones). Sólo ocasionalmente nos encontramos con una lúcida excepción, como cuando la originalidad y la postura valiente de los ensayos de Rochberg, sobre 
la música de nuestro tiempo, brilla en el horizonte. Ciertamente, más opúsculos de este tipo disolverian muchas de las nubes ostentosas y amenazantes que cuelgan sobre buena parte de la música culta del siglo $X X$.

Siendo la música la más abstrata de todas las artes, es, sin embargo, la mas emocional de todas. Aunque en realidad la música no puede crear imágenes concretas, es inegable que es capaz de evocar fuertes emociones, haciendo vibrar el sistema nervioso y produciendo misteriosas asociaciones simbólicas que se transforman en sensaciones relacionadas con imágenes que se antojan reales para el oyente. Cuando estas imágenes logran comunicar emociones a través de la recreación de memorias y la repetición de las mismas - bien sean estas transmitidas por líneas melódicas, por actividad rítmica, por conglomerados de tonos verticales o por el color instrumental y vocal manejado inteligentemente - el ser humano que las recibe goza plenamente la experiencia. Aunque la música es posiblement la forma más antigua de expresión (algunos antropólogos han apuntado que el hombre cantó primero antes de que pintase o esculpiese) la misma demoró milenios en transformarse en una expresión artística abstracta e independiente, capaz de crear sus propias leyes ordenadas de arquitectura y conception formal. En cierto momento, en culturas desarrolladas, la música se dividió en dos entidades: una no utilitaria y progresivamente más intelectualizada, y otra más simplista y repetitiva, unida a la danza y a la canción de tipo popular. Tal ha sido la evolución de estas dos facciones en direcciones diferentes que a mediados del siglo $\mathrm{XX}$ el único común denominador entre las dos es el sonido: la filosofía, el vocabulário, la forma, la intención y el propósito de ambas es tan diferente que las dos se encuentran en polos opuestos.

Desde un punto de vista lógico el inevitable desarollo intelectual de la música culta dio por resultado la total atomización del ritmo, la melodia, la relación vertical y la forma. Pero la lógica y la expresion artística necesariamente no van juntas. En un momento dado de nuestro siglo la música cayó bajo el encantamiento del Expresionismo centroeuropeo - un intenso movimiento estético, emocional, político y religioso, y quizás históricamente inevitable, que llegó a fascinantes consecuencias extremas. De pronto, las expresiones artísticas se volvieron angustiosas $\mathrm{y}$, mas tarde, a menudo estériles. La música, como las otras artes, entró al reino del absurdo, llegando a su zenit total en la obra silente de Cage 433". Con la destrucción final de los únicos eslabones que podía hacerla comprensible al público en general (básicamente la eliminación de patrones melódicos y rítmicos, y la desaparición de estructuras reconocibles y del desarrolo repetitivo) la música atonal perdió el contacto con los oyentes. Es significativo el observar que hasta los años de la Primera Guerra Mundial, un educado amante de las artes gozaba la pintura de vanguardia de su tiempo, le conmovian los poetas de su época histórica, y estaba al tanto del teatro de su momento: era la misma persona que viajaba muchas millas para oír la última ópera de Richard Strauss... Ochenta años después esse mismo ser humano sensible a diversas clases de expressiones artísticas, que cuelga en sus paredes serigrafías de Miró o de Kandinsky (u otros pinto- 
res semejantes que requierem inversiones más modestas), que va al teatro para ver obras de Sartre o de Albee, que conoce las novelas de Falkner o de García Márquez, cuando se le pregunta qué música le gusta contesta en forma non-sequitur, expresando su amor por los compositores barrocos o por las manifestaciones de la música rock. ?Qué ha ocurrido? Simplesmente, el susodicho amante de las artes no puede apreciar la música de arte de su época en el mismo nivel emocional e inteligible en el que digiere las otras expresiones artísticas, aún cuando jamás antes había sido bombardeado con tal número de explicaciones, con tal variedad de intensa propaganda, y con argumentos que se suponen convincentes para hacerle entender la denominada "expresión musical culta" de su día. Muchas soluciones se han propuesto para resolver este curioso y dramático crucigrama, desde un regreso a la tonalidad (como se escucha en las obras más recientes de Penderecki) a una radical simplificación del vocabulário musical (como aparece en las obras de los minimalistas). Lo que es evidente es que el compositor de música seria de hoy debe mantener su integridad estética al mismo tiempo que necesita encontrar un lenguage musical que, sin llevarlo de lleno al pasado, produzca nuevamente una renovación del proceso de comunicación auditiva entre el creador y el oyente. Esta obsesión por crear una música que sea a la vez impactante emocionalmente y asimismo exponente de un alto nivel artístico (y que por tanto sea capaz de transformar el mero material sónico de expression simplista en una verdadera, decantada y refinada inventiva creadora) es la máxima preocupación de muchos compositores de música de arte de hoy.

El advenimiento del mundo schoenbergiano marco la aparicion permanente del angst en la música de arte. La música anti-angustiosa de compositores como Satie y sus herederos del grupo de Les Six (quienes elogiaban las glorias de la Torre Eiffel, y el ir y venir de marineros, prostitutas, jugadores de fútbol y locomotoras) se vio en corto tiempo obliterada por el regreso avasallador de la hegemónia de la música alemana - un edificio granítico donde Debussy, Ravel, Falla, Malipiero y Milhaud esculpieron escasamente unas pocas líneas. Otro grupo de compositores (la falange Stravinsky-Bartok-Prokofieff) estableció por un tiempo impresionantes cabezas de playa que en los años veinte y treinta parecieron ganar el primer puesto. Pero cuando terminó el paréntesis de la Segunda Guerra Mundial se vio claramente que el trinomio vienés Schoenberg-Berg-Webern había obtenido un completo triunfo, llegando a penetrar y conquistar a Francia, a Italia, a Inglaterra, a España y a las Américas. Cuando Stravinsky escribió su Septeto de 1952-1953, el último obstáculo que quedaba desapareció. A partir de entonces el credo de Schoenberg (y asimismo el de Webern) ejercio una poderosa fascinación sobre los compositores jóvenes. En poco tiempo la creatividad musical se volvió o neurótica o numerologica. La Caja de Pandora que el binomio Schoenberg-Freud había abierto fue de lo físiológico a lo técnico, y el lenguage musical tiró por la borda no sólo las formaciones tonales sino toda una serie de formulas estéticas decantadoras, abriendo así el camino hacia la exaltación de lo horrísono. Con la aparición de la no-repetición y del concepto del fluir de la consciencia, de- 
sapareció toda idea direccional, y los estados de ánimo suplantaron la estructura; et color, en lo instrumental y en los conglomerados sonoros verticales, y el texto, en las obras vocales, vinieron a ser los únicos nexos entre el compositor y el auditor. Inmediatamente aparecieron el ruido y la atomización microtonal, y, por vez primera en la históreia de la música, lo intrínsicamente feo (esencialmente considerado, sin nengún trasfondo ilustrativo, dramático o narrativo) fue elevado a categoría estética. El abandono de tantos parámetros técnico-estéticos vino a limitar el fin comunicativo de todo lenguaje musical, con la subsiguiente deserción del espectador de la sala de conciertos.

El compositor español Gonzalo de Olavide, en su excelente y penetrante artículo-ensayo El limite y el país fértil, aparecido en "Saber" (No 39; Madrid, noviembre de 1990), apunta que "es curioso cómo en la mitad de siglo en que el compositor en cierta manera realiza su universo de espaldas al público, por tachar su escucha de superficial, sea precisamente éste el que con su ausencia ponga en evidencia una de las problemáticas más agudas por la que pasa el arte (musical) de este momento, y una vez confinada al ghetto, la música contemporánea se presenta como especialización cortada de toda filiación histórica... Se habla de música contemporánea (de arte) como se menciona y denomina un subproducto, pero en ningún caso de música de nuestro tiempo". Si retomamos la época de la atonalidad veremos que lo que al principio pareció ser una liberación y una nueva frontera muy pronto se convertió en un panorama monocolor, donde un constante cromatismo liquidó todo punto de referencia. Los textos expresionistas vinieron a darle al tortuoso lenguage sonoro la única posibilidad de mantener la atención del oyente por un período de tiempo más allá de unos pocos minutos. Pero con estos textos la angustia auditiva se transformó también en una emocional y tensa totalidad. Un solemne requiescat in pace a la alegría, a la simplicidad, a la relajación, al esparcimiento, al humor, a la comedia, a la ligereza y a lo reconocible permeo el panorama. El resultado final fue la muerte de la creatividad musical como manisfestación estética llena de comunicativa luminosidad. La música se transformó así en un fenómeno artístico creativo no concebido para ser gozado sino para ser sufrido y analizado, no para identificarse con él sino para alienarse de él. Anõs más tarde, con la aparición del culto weberniano y las subsiguientes codificaciones de la Escuela de Darmstadt, la espontaneidad fue criticada, y el escribir una pieza de música se convertio en un fidedigno teorema, incluyendo toda clase de implicaciones filosóficas, matemáticas y extra musicales. Aún una mente brillante como la de Boulez - quien en vuelta de hoja camaleónica "a lo Picasso" tratará más tarde, en su reciente libro Jalons (Christian Bourgois Ed.,Paris, 1989), de demonstrar el sin sentido del sistema serial - se torno creativamente casi paralizada, puesto que la próxima obra a ser compuesta tenía que ser a priori tan perfecta en todos sus aspectos y ángulos artísticos, poéticos, filosóficos, científicos y menudo hasta políticos (siempre y cuando proviniesen más o menos directamente a los postulados de la izquierda marxista intelectual) que el compositor se quedó más de una vez anonadado frente al pentagrama. Seguidamente aparecieron, como por parte 
de magia, colecciones completas de obras musicales que eran prologadas por tres hojas de explicaciones para cada página de música que contenían - fenómeno éste que seguramente constituirá un documento fascinante para que las generaciones futuras evaluen y estudien nuestro tiempo. Webern vio el perigro de la neurosis abrasadora de la estética schoenbergiana y optó por trabajar con las derivaciones puras del sistema de los doce tonos. Mientras Schoenberg sintió a mediado de los años veinte la necesidad de resucitar las viejas formas, la repetición y aún las estructuras rítmicas, Webern evitó la trampa siguiendo el principio de variación constante enmarcado por los doce semitonos serializados, abandonando toda otra consideración metafísica. Los procedimientos de Webern dejaron de lado la angustiosa paleta expresionista, pero abrieron de par en par las puertas a innumerables epígonos de menor categoría quienes, ajenos al fino lirismo de Webern, a menudo produjeron tristes caricaturas basadas en el constante repetir de aburridas y secas fórmulas seriales. Stravinsky fue el último converso al serialismo (siguiendo la vision de Webern y no el paroxismo de Schoenberg) quien debido a su increíble poder creativo y natural intuición musical fuc capaz de componer obras estructuradas serialmente y en su mayoría comunicativas sin sucumbir jamás a la tentación de inventar constantes explicaciones de sus composiciones o de dedicarse a la caza de prosélitos. Su música de los años sesenta y setenta, única en su clase, cierra en muchas formas una era de la música del siglo $\mathrm{XX}$. Stravinsky mismo pensaba que The Rake's Progress era el final de un largo proceso estilístico en la historia de la música occidental y se sintió lleno de nueva vida al adoptar el serialismo. Tal vez él es hasta ahora el único compositor que ha tenido el honor de cerrar dos eras musicales dentro de un cortísimo período de tiempo.

Después de la esterilidad y la idiotez de mucha de la música escrita en los cincuenta y los sesenta, hay señales que indican un retorno a un renovado balance entre el intelecto y la emocion. Por ejemplo, la sana postura anti-serialista de la escuela polaca en años recientes produjo de nuevo una comunicación emocional entre eł creador y el oyente, siendo las nuevas proposiciones formales y el calor expresivo del lenguaje sonoro un refrescante cambio. Asimismo, dentro de la producción de música culta contemporánea proveniente de Latinoamérica, la cual ha sido vastamente ignorada, varios compositores provenientes de esa parte del mundo ofrecen ejemplos de una música que no sólo tiene una voz propia que no ha sido infestada con europaesclerosis sino que exhibe una ingenuidad refrescante cargada de comunicatividad expresiva y de impacto dramático. Si existe un área en el mundo donde está presente la bienvenida ausencia de las tácticas de venta de una bien engrasada maquinaria publicitária, que promueve productos musicales de dudosa calidad, ese lugar es evidentemente América Latina. Si Alberto Ginalstera hubiera sido alemán, y Claudio Santoro norteamericano, y si Marlos Nobre fuese francés, Mario Lavista italiano, Edgar Valcárcel sueco, Alfonso Letelier holandés, Roque Cordero austríaco, Manuel Enríquez suizo, Alfredo Rugéles inglés, Gilberto Mendes japonés, o Juan Orrego Salas ruso, la música de cada uno de ellos hubiera sido constantemente exaltada y promovida calurosamante. De 
hecho, estos compositores nunca sucumbieron a la progresiva y antihumana enfermedad que llevó a un punto de paralización a una gran cantidad de música culta del siglo $X X$. En un futuro, cuando las aguas regresen de nuevo a su nivel, mucha de esta música latinoamericana será justamente reconocida y apreciada.

La crisis de la música culta del siglo $\mathrm{XX}$ es la crisis del hombre moderno. La proclamacion de una lógica artística interna distinta a la lógica de la realidad, constituyó una proclama novedosa y encubridora que en un momento dado parecía ser revolucionária y refrescante. Pero los contínuos extremismos subsiguientes transformaron este desarollo en una simple revuelta autogratificadora. Tras destruir hasta el último vestígio tradicional, los Jóvenes Turcos musicales del momento no se detuvieron para construir una nueva geometría artística. Por el contrário, continuaron aplastando las ruinas humeantes hasta que no quedó nada salvo el vacio total. Como apunta Olavide en el ya citado artículo, el compositor de música culta se convertió en un sumo sacerdote omnipersonal que, de espaldas a la memória corretiva sin romper sus nexos con la sociedad, nutriendo su parte de la constante interacción entre inventor y receptor, comenzó a expresarse en un lenguaje secreto al que solo él tenía acceso y que a menudo era externo y ajeno al lenguaje musical. El completo divórcio de la realidad musical milenaria (exacta altura reconocible de sonidos, actividad motívica, desarollo de ideas, complejos verticales funcionales, estrucuras perceptibles) llevó al compositor de música culta a un páramo donde de pronto se encontró solo, totalmente aislado del público para el cual creía que estaba creando desconocidos y excitantes sonidos. Destruída la forma, el tema (aquella sucesión organizada y accesible de sonidos que siempre había comunicado ideas por estar concebida dentro de cánones estructurados, los cuales, de un modo u otro, se hallaban basados en un lenguage general que abarcaba la expresión y concepción de melodias que podían ser sencillas y directas (populares, folklóricas) o más evolucionadas y trabajadas, como eran las que se movían dentro del marco más abstracto de lo artístico) se convertía en una sucesión amorfa de sonidos e intervalos cuyo sentido el oído era ahora incapaz de detectar. Si la labor del compositor había consistido siempre en ordenar los materiales sonoros para conformarlos a una idea capaz de establecer comunicación entre él y el auditorio, a medio siglo $X X$, convertido en todopoderoso, el creador musical pretendía hacerse presente sin tomar en cuenta el límite de lo perspectivo, lo cual producía un caos no ya creativo sino hiperestésico. A través de la época moderna quien, aún en sus obras más extremadamente intelectuales, nunca perdió el sentido de la otra realidad - principalmente la habilidad de comunicarse con su audiencia, combenando a este fin su tan individual estilo rítmico y armónico con un agudo, claro, brillante y curiosamente objetivo lenguaje musical, lo cual le permitió balancear los más intrincados procedimientos seriales consecciones de gran sonoridad vertical nunca desprovista de inteligibilidad.

Tristemente, la música culta del siglo $\mathrm{XX}$, tan obsesivamente preocupada con la técnica, perdió el elevado y singular lugar que había ocupado previa- 
mente durante los siglos en que actuó como una expresión sofisticada, y a la vez real y vital, de culturas sucesivas. Según la música culta se fue volviendo más esotérica, el público se fue acercando más y más a la significativa y creciente corriente de la música popular que surgió despues de 1900 - corriente que incluye el jazz, los blues, la rumba, el bolero, el swing, el tango, el beebop, la samba, las diversas formas del rock, el corrido, el mambo y tantas otras manifestaciones similares. Los llamados "compositores de vanguardia" de los años cincuenta y sesenta, en su inquieta y ciega búsqueda de lo nuevo a toda ultranza, propusieron una nueva definición de la música que ignora profunda e intensamente cualquier intento de explicación estructurada de la misma. Pero esta definición - que se convertió en total aislamiento y enajenacion, escibiendo los compositores sólo para otros compositores - era totalmente egoísta y egocéntrica, y no tuvo ninguna unión substancial con la más elemental, mínima, posible y lógica percepción auditivo estructural.

Eventualmente, el dadaísmo a lo Cage, el minimalismo (tan vinculado al culto de los alucinógenos), los procedimientos aleatorios totales (que cubrían mucha esterilidad creativa), los meros recorridos mentales por otras galaxias, olvidando que los pies seguían en la tierra, pasarán finalmente de moda en proporción inversa al crecimiento de una música culta nueva que tendrá su base en un renovado lenguage plenamente estructurado. El compositor de música de arte de hoy tiene que desarticular el término música contemporánea para que su música vuelva a ser un gesto libre creativo donde la forma vuelva a reinar por sobre la idea, ajena a estériles cappilismos formularios que han producido la erosión del amor, el respeto, y la emocionante apreciación que la música culta había tenido siempre. Entonces, los compositores de esta música seria revigorada podrán recuperar un lugar en la sociedad de su momento, y encontrarán otra vez, sin repetir las experiencias pasadas, el eslabón perdido que mantuvo siempre a la música, no importa que cambios estilísticos la modificaran, maravillosamente vital, generadora de emoción y a la vez de comprensible intelectualidad, en el seno de una cultura dada.

Los Angeles, noviembre de 1990

Aure lio de la Vega, nacido en La Habana el 28 de noviembre de 1925, reside an Los Angeles desde 1959, y es Compositor-en-Residencia y Profesor Distinguido de la Universidad Estatal de California en Northridge. 